finger into the rectum, and found the invaginated gut had disappeared. I prescribed small doses of opium and left. The next morning I called expecting to hear my little patient was defunct, but, to my surprise, the mother in formed me that she had not been sick since I left, and that, although there was a little mucus passing every hour or so, there was no tenesmus. The abdomen was softer, and could be couched without making the child cry, and no tumour could be detected. The rectum was also quite empty. I ordered white of egg in a little water and a little veal broth at frequent intervals, and to continue with the opium mixture. The child made an uninterrupted recovery.

I think this case worthy of reporting on account of the length of time the gut was invaginated (nine days). As far as $I$ know it is the first successful case that has been replaced by inflation after so long a period. I should have thought that after nine days adhesions would have taken place, and that any attempt at reposition would have proved fatal by rupture. This is the second successful case I have had ; the first one I saw on the second day, and used the same treatment. It also shows the great help of an anæsthetic both in the diagnosis and in the treatment, for until the infant was thoroughly under I could feel nothing definite, and as regards the treatment it is no less important. This case, when taken with other successful cases, will encourage others to try the same treatment before opening the abdomen, which operation, especially in a Bush practice, does not hold out any great hope of success.

Millicent, South Australia.

\section{GURJUN OIL AS AN EXPECTORANT.}

By William Murrell, M.D., F.R.C.P.,

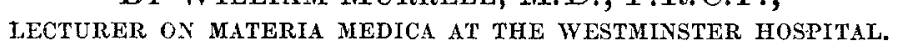

A FEW weeks ago, in a communication to THE LANCET, I stated that at the suggestion of Dr. Walshe I had been using copaiba as a remedy for chronic bronchitis and winter cough. I found that it was an excellent expectorant, but had this grave disadvantage-that in a large proportion of cases it brought out a rash attended with intense itching, and often accompanied by irritation of the throat, diarrhoea, and vomiting. To obviate this difficulty I endeavoured to find some drug allied to copaiba which would exert the required action on the bronchial mucous membrane without affecting the skin. After one or two unsuccessful trials I thought of gurjun oil, which at one time was extensively used to adulterate copaiba. Gurjun balsam or wood oil, as is well known, is a balsamic exudation obtained by incision and the application of heat from the trunk of Dipterocarpus turbinatus and other species growing in the East Indies. It is a transparent liquid of the consistence of olive oil, of an opaque, dingy, greenish-grey colour, as seen by reflected light, and having an aromatic odour and taste not unlike that of copaiba, but without its acridity. Some years ago it was brought prominently into notice by Dr. Dougall of the Andamans as a remedy for leprosy, hut seems to have attracted but little attention in this country. There is practically no demand for it here as a therapeutic agent, and it is a very inexpensive drug. I gave it first in doses of a drachm and then of two drachms three times a day, enough being ordered to last a week. I prescribed it in the furm of a mixture, with liquor potassæ, spirit of nitrous ether, mucilage of acacia, and cinnamon water. It certainly was not a very inviting combination, especially as it had a tendency to "curdle," but it seemed eminently adapted for exciting a rash if the drug were eliminated by the skin. After a time I gave it mixed with extract of malt-two drachms of the balsam to an ounce of the extract-three times a day, and this was taken without difficulty. The chronic bronchitics-many of whom had previously taken copaiba-reported that it acted admirably as an expectorant, "clearing the chest" and easing the cough. In several cases I gave in addition tincture of jaborandi or nitrate of pilocarpine at bedtime so as to produce profuse sweating, but no eruption resulted. My colleague, Dr. Colcott Fox, tells me that there are one or two cases of gurjun rash on record, but I have not been fortunate enough to see one. It is true one patient-a woman-told me that the medicine brought out some spots, but they disappeared in a few hours, and increasing the dose failed to reproduce them. It seems to me that gurjun oil has all the advantages of copaiba as an expectorant, without the grave disadvantage of exciting an eruption. It has been recommended as a remedy for gonorrhoea and gleet, but I have had no experience of its use in this direction. Weymouth-street, W.

\section{A CASE OF DIPHTHERITIC PARALYSIS IMPLI. CATING LARYNGEAL MUSCLES.}

\section{By JaMes B. BALL, M.D., M.R.C.P.,} PHYSICIAN TO THE THROAT DEPARTMENT, AND SENIOR ASSISTANT PHYSICIAN, WEST LONDON HOSPITAL.

W. Y-, aged twenty, a milkman by calling, was admitted into the West Condon Hospital on May 31st, 1889, suffering from weakness of the legs, hoarseness, and other troubles. I am indebted to Dr. Herringham, under whose care he was, for the opportunity of examining the patient's larynx, and for permission to make use of the notes of the case. The following history was obtained:- He had always enjoyed good health. Ten weeks previously to admission he got a cold, and lumps formed at the side of his neck. He did not lie up or consult a doctor; the cold gradually got better, and the lumps went down. Three weeks before admission his voice began to get weak, and he had difficulty in calling "Milk" on his rounds. About a week later, he became rather suddenly very weak on bis legs and had to take to his bed, where he continued until admission. About the same time that he took to his bed he found that fluids used to come through his nose in drinking.

On admission, he was rather pale. His pupils were normal and equal, and reacted well to light and accommoda. tion. There was no facial paralysis and no weakness of the arms. His fingers felt dead; his feet were numb. The knee-jerks were absent. The gait was reeling, and he required assistance in walking. The urine contained no albumen. The voice was hoarse and had a nasal twang. He could swallow solids well, but fluids returned through the nose, and some went "the wrong way" and made him cough. The soft palate moved slightly on the right side in phonation, but the left side did not move. The sensation of the palate and pharynx was apparently much diminished. On June 3rd I exanined his larynx. The colour and conformation of the parts were normal. The left vocal cord lay motionless in the cadaveric position. The right vocal cord moved well, but in phonation was curved, with the concavity inwards, from loss of tension. About a week after admission fluids ceased to come through the nose; otherwise hiscondition remained much the same till June 15 th, when his gait was noted as being steadier and his voice stronger. His lef $t$ vocal cord, however, was still motionless, but the right cord had recovered its normal tension. On June 22nd the left cord moved up to the middle line in phonation, but was not abducted much, if at all, beyond the cadaveric position, with deep inspiration. His voice at this time was good, except for the nasal twang. On July 7th he was discharged from the hospital. His general condition had much improved. He could walk steadily, but his legs soon got tired. The numbness of his hands had somewhat increased. The grasp of the right hand was weak and there was slight incoördination in the movements of the hand. The movements of the soft palate were more free than on admission, but were still imperfect on the left side. The voice had a slight nasal twang, but was otherwise good. The abduction movement of the left vocal cord was still impaired. The treatment throughout his stay in the hospital consisted of ten-drop doses of tincture of nux vomica, with nitro-muriatic acid, three times daily. The patient was lost sight of after leaving the hospital. I saw him, however, in the early part of last February, and he stated that he lost all numbness of his hands and feet, and gained his usual walking powers and natural voice, about two months after leaving the hospital, and he was able to resume his usual work. At the time I saw him his knee-jerks were present, and the movements of his palate and rocal cords were normal. Although the actual nature of the so-called cold which this patient had suffered from, ten weeks before admission, was not determined at the time of its occurrence, there can be no doubt, from the subsequent course of the case, that it was an attack of diphtheria.

Wimpole-street, W. 